\title{
Comunicação
}

[Communication]

\section{Sorodiagnóstico de doenças da reprodução em rebanhos de bovinos leiteiros de assentamentos rurais de Corumbá, MS}

[Reproductive diseases serosurvey in dairy cattle from rural settlements of Corumbá city, Mato Grosso do Sul state, Brazil]

\author{
R.G.P. Tomich ${ }^{1,2}$, C.V. Serra ${ }^{3}$, M.R.Q. Bomfim ${ }^{1}$, F.S. Campos $^{4}$, Z.I.P. Lobato ${ }^{4}$, A.O. Pellegrin ${ }^{2}$, L.A. \\ Pellegrin $^{2}$, E.F. Barbosa-Stancioli ${ }^{1 *}$ \\ ${ }^{1}$ Instituto de Ciências Biológicas - UFMG \\ Caixa Postal 486 \\ 31270-901 - Belo Horizonte, MG, \\ ${ }^{2}$ Embrapa Pantanal - Corumbá, MS \\ ${ }^{3}$ Lanagro/MG - MAPA - Pedro Leopoldo, MG \\ ${ }^{4}$ Escola de Veterinária - UFMG - Belo Horizonte, MG
}

$\mathrm{Na}$ região de Corumbá/MS, existem oito assentamentos rurais que, juntos, totalizam 1.431 lotes. O Mato Grosso do Sul é um dos principais estados produtores de gado de corte do país, e o município de Corumbá concentra um dos maiores rebanhos de cria, sendo o bezerro seu principal produto de venda. Assim, o estabelecimento de programas de controle de doenças da reprodução, tais como as causadas pelo vírus da rinotraqueíte infecciosa bovina (Herpesvirus bovino $1-\mathrm{BoHV}-1$ ), pelo vírus da língua azul (BTV) e pela Leptospira, agentes relacionados a quadros subclínicos em regiões endêmicas, com ocorrência de aborto, retenção de placenta, repetição de cio e infertilidade, assumem maior importância para a bovinocultura dessa região.

Vários autores citam alta frequência de sorologia positiva para esses agentes nos rebanhos brasileiros (Favero et al., 2001; Konrad, 2003; Araújo et al., 2005). Em Corumbá, os poucos estudos realizados indicam a ocorrência da infecção por BoHV-1, BTV e Leptospira em rebanhos de gado de corte criados na região de planície desse município (Pellegrin et al., 1997, 1999). O presente estudo teve como objetivo determinar a soroprevalência desses agentes nos rebanhos dos assentamentos rurais da reforma

Recebido em 3 de julho de 2008

Aceito em 16 de abril de 2009

* Autor para correspondência (corresponding author)

E-mail: edelfb@icb.ufmg.br agrária, localizados na região de planalto e composto, sobretudo, por rebanhos leiteiros.

Foram avaliados quatro assentamentos (Fig. 1) cuja bovinocultura leiteira destaca-se como importante atividade econômica. O número de lotes desses assentamentos e as respectivas áreas e o número aproximado de bovinos são apresentados na Tab. 1. Para o cálculo do tamanho mínimo da amostra, foi utilizado o programa Win Episcope. O cálculo foi realizado com base na prevalência esperada de $50 \%$, precisão de $10 \%$ e intervalo de confiança de 95\%. Foi considerado como universo amostral o efetivo bovino estimado, para cada assentamento (Tab. 1). A amostra ficou assim dividida: 86 soros bovinos originados de rebanhos do assentamento Mato Grande, 74 do Paiolzinho (exceto para análise de BoHV-1 cujo total de soros foi 73), 95 do Tamarineiro II e 98 do Taquaral (exceto para análise de Leptospira cujo total de soros foi 94). A soma total resultou em 353 soros. Destes, 27 eram de bezerros(as), 66 de novilhos(as), 183 de vacas, 13 de touros e 64 eram soros cuja identificação não continha a idade do animal.

Essas amostras foram escolhidas aleatoriamente em um banco de soros contendo 1097 soros coletados no mês de julho de 2003. A distribuição espacial dos rebanhos avaliados é apresentada na Fig. 1. 


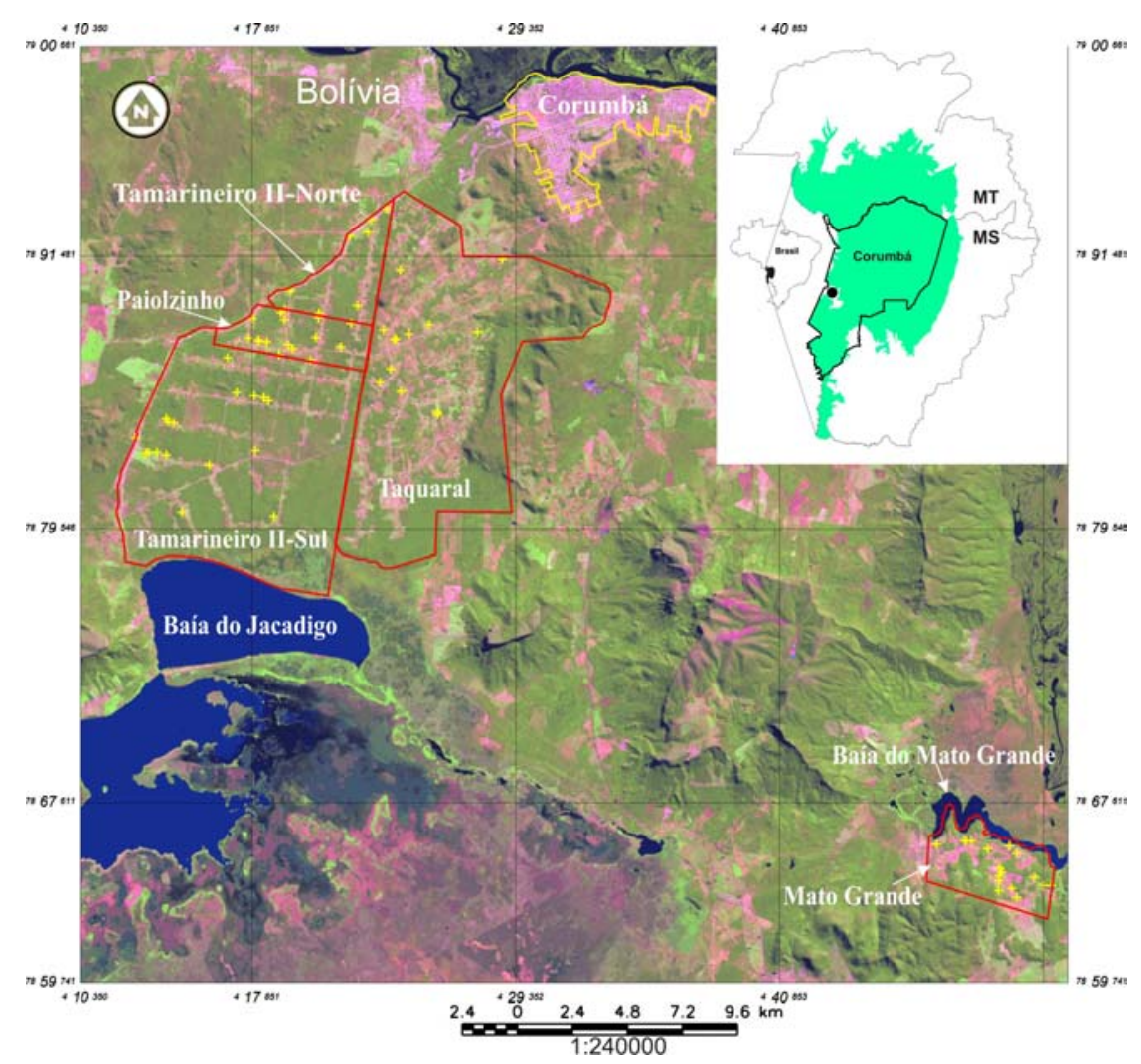

Figura 1. Localização do Pantanal brasileiro (cor verde) e do município de Corumbá, MS. O ponto preto indica a localização aproximada da cidade de Corumbá e dos assentamentos rurais (mapa superior à direita). Delimitação da cidade de Corumbá e dos assentamentos Mato Grande, Paiolzinho, Tamarineiro II (glebas norte e sul) e Taquaral, mostrando a proximidade com a Bolívia. Distribuição espacial dos rebanhos bovinos amostrados (cruzes de cor amarela - um rebanho do Paiolzinho e outro do Tamarineiro II não estão representados no mapa). Coleta de amostras de soro bovino realizada em 2003. Localização por "global positioning system" (GPS) e inserção em imagem de satélite Landsat banda 4.

Tabela 1. Caracterização de quatro assentamentos rurais de Corumbá/MS: número de lotes, área total e efetivo bovino aproximado*

\begin{tabular}{lccc}
\hline \multicolumn{1}{c}{ Assentamento } & $\begin{array}{c}\text { Número de lotes } \\
\text { (parcelas) }\end{array}$ & Área (hectares) & $\begin{array}{c}\text { Bovinos } \\
\text { (unidade animal) }\end{array}$ \\
\hline Mato Grande & 50 & $1.264,35$ & 750 \\
Paiolzinho & 70 & $1.196,75$ & 400 \\
Tamarineiro II & 319 & $10.621,08$ & 1.500 \\
Taquaral & 394 & $10.013,24$ & 4.000 \\
\hline
\end{tabular}

*Dados fornecidos pelo Instituto de Desenvolvimento Agrário, Pesquisa, Assistência Técnica e Extensão Rural do Mato Grosso do Sul - IDATERRA e pelo Instituto Nacional de Colonização e Reforma Agrária, Superintendência Regional de Mato Grosso do Sul - INCRA-MS

Para o diagnóstico sorológico dos agentes pesquisados, foram usados os métodos preconizados pela Organização Mundial de Saúde Animal (Manual..., 2004). Para o BoHV1 , foi utilizado o teste de soroneutralização viral de acordo com Soares e Pereira (1980). Amostra viral padrão Colorado-1 (Cooper) (ATCC VR864) foi utilizada como antígeno (Ag). Amostras com título de anticorpos $(\mathrm{Ac}) \geq 2$ foram definidas como positivas. Para a detecção de Ac contra o BTV, foi utilizada a técnica de dupla difusão em gel como descrito por Pearson e 
Jochim (1979). O antígeno e o soro controle positivo utilizados foram o $\mathrm{Ag}$ produzido no Departamento de Medicina Veterinária Preventiva da Escola de Medicina Veterinária da UFMG e um conjunto de soros positivos testados frente a um Ag padrão (Ames - partida 638102). Para a detecção de anticorpos antileptospira, foi utilizada a reação de soroaglutinação microscópica segundo Faine (1982). Culturas vivas de amostras de 21 sorovares de Leptospira, provenientes do laboratório de referência Royal Tropical Institute, Amsterdã, Holanda, foram usadas como antígenos. Foi considerado como ponto de corte o título $\geq 100$.

Os resultados obtidos nas análises sorológicas foram armazenados em um banco de dados formatado por meio do programa Epi Info versão 3.3.3. O teste de qui-quadrado $(\chi 2)$ foi utilizado para testar as hipóteses de associações entre as frequências de animais positivos para os agentes estudados e o assentamento avaliado ou a categoria do animal, com $\mathrm{P}<0,05$.

Os resultados encontrados indicam soroprevalências para BoHV-1, BTV e Leptospira iguais a 50,9\%, 51,3\% e $35,8 \%$, respectivamente (Tab. 2): 13,2\% (46/348; IC $95 \%=9,9 \%-17,3 \%$ ) das amostras foram positivas, ao mesmo tempo, para os três agentes, $28,7 \%(100 / 348 ;$ IC $95 \%=24,1 \%-33,9 \%)$ para um dos agentes e 35,1\% (122/348; IC 95\%= $30,1 \%-40,4 \%$ ) para dois deles. O percentual de amostras negativas para os três agentes foi de $23,0 \%(80 / 348 ;$ IC $95 \%=18,7 \%-27,8 \%)$. Essas respostas sorológicas refletem infecções naturais, uma vez que os rebanhos amostrados não são vacinados para os agentes pesquisados.

Tabela 2. Soroprevalência do Herpesvírus bovino 1 (BoHV-1), vírus da língua azul (BTV) e Leptospira em criações de bovinos leiteiros de quatro assentamentos rurais de Corumbá/MS, 2003

\begin{tabular}{|c|c|c|c|c|c|c|}
\hline \multirow[b]{3}{*}{$\begin{array}{l}\text { Assentamento } \\
\text { rural }\end{array}$} & \multicolumn{6}{|c|}{ Amostra positiva (soro) } \\
\hline & \multicolumn{2}{|c|}{ BoHV-1* } & \multicolumn{2}{|c|}{$\mathrm{BTV}^{*}$} & \multicolumn{2}{|c|}{ Leptospira** $^{* *}$} \\
\hline & $\mathrm{n} / \mathrm{N}$ & $\begin{array}{c}\% \\
\text { (IC } 95 \%)\end{array}$ & $\mathrm{n} / \mathrm{N}$ & $\begin{array}{c}\% \\
\text { (IC 95\%) }\end{array}$ & $\mathrm{n} / \mathrm{N}$ & $\begin{array}{c}\% \\
(\mathrm{IC} 95 \%)\end{array}$ \\
\hline Mato Grande & $49 / 86$ & $\begin{array}{c}57,0 \\
(45,8-67,6)\end{array}$ & $53 / 86$ & $\begin{array}{c}61,6 \\
(50,5-71-9)\end{array}$ & $32 / 86$ & $\begin{array}{c}37,2 \\
(27,0-48,3)\end{array}$ \\
\hline Paiolzinho & $42 / 73$ & $\begin{array}{c}57,5 \\
(45,4-69,0)\end{array}$ & $31 / 74$ & $\begin{array}{c}41,9 \\
(30,5-53,9)\end{array}$ & $34 / 74$ & $\begin{array}{c}45,9 \\
(34,3-57,9)\end{array}$ \\
\hline Tamarineiro II & $40 / 95$ & $\begin{array}{c}42,1 \\
(32,0-52,7)\end{array}$ & $48 / 95$ & $\begin{array}{c}50,5 \\
(40,1-60,9)\end{array}$ & $38 / 95$ & $\begin{array}{c}40,0 \\
(30,1-50,6)\end{array}$ \\
\hline Taquaral & $48 / 98$ & $\begin{array}{c}49,0 \\
(38,7-59,3)\end{array}$ & $49 / 98$ & $\begin{array}{c}50,0 \\
(39,7-60,3)\end{array}$ & $21 / 94$ & $\begin{array}{c}22,3 \\
(14,4-32,1)\end{array}$ \\
\hline Total & $179 / 352 a$ & $\begin{array}{c}50,9 \\
(45,5-56,2)\end{array}$ & $181 / 353$ & $\begin{array}{c}51,3 \\
(45,9-56,6)\end{array}$ & $125 / 349 b$ & $\begin{array}{c}35,8 \\
(30,8-41,1)\end{array}$ \\
\hline
\end{tabular}

*Não houve associação entre a frequência de animais positivos para o agente e o assentamento rural $(\mathrm{P}>0,05)$ pelo teste $\chi 2$. **Houve associação entre a frequência de animais positivos para o agente e o assentamento rural $(\mathrm{P}<0,01)$ pelo teste $\chi 2$. $\mathrm{n} / \mathrm{N}=$ número de amostras positivas/número total de amostras analisadas; IC $95 \%=$ intervalo de confiança a $95 \%$ de probabilidade

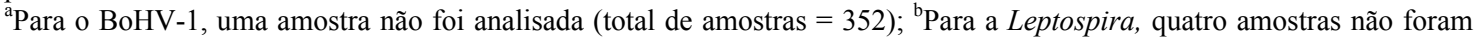
analisadas (total de amostras $=349$ ).

Altas soroprevalência para a infecção por BoHV1, como a encontrada para os rebanhos dos assentamentos rurais estudados, indica a possibilidade de presença de animais com infecção latente. Esses animais são portadores inaparentes do vírus. Reativações periódicas da infecção, desencadeadas por fatores imunossupressores, geralmente ocasionam eliminação de grande quantidade de vírus e o animal assume papel importante na cadeia epidemiológica da doença.
Com relação ao BTV, levantamentos sorológicos incluindo diferentes espécies de ruminantes domésticos (bovinos, ovinos, caprinos, bubalinos) têm evidenciado a presença de animais soropositivos para esse vírus em muitos estados brasileiros (Lage et al., 1996; Konrad, 2003; Costa et al., 2006), incluindo o Mato Grosso do Sul (Pellegrin et al., 1997), sem, contudo, detectar sintomatologia clínica. O BTV é transmitido por dípteros do gênero Culicoides. Como toda doença cuja transmissão é 
dependente de vetores, a epidemiologia do BTV consiste em uma interação complexa e dinâmica envolvendo o hospedeiro, os diferentes sorotipos virais, os vetores, o clima e suas inter-relações.

Na região deste estudo, a temperatura média no inverno varia de $17,7^{\circ} \mathrm{C}$ a $27,4^{\circ} \mathrm{C}$ e no verão de $23,4^{\circ} \mathrm{C}$ a $32,8^{\circ} \mathrm{C}$, e a média anual de precipitação pluviométrica é $1.070 \mathrm{~mm}$ (Soriano, 1997); condições favoráveis ao desenvolvimento de Culicoides durante todo o ano. Ward (1994) observou que um aumento de $20 \%$ na média de precipitação atmosférica (de $799 \mathrm{~mm}$ para $959 \mathrm{~mm}$ ) e de $3^{\circ} \mathrm{C}$ (de $29^{\circ} \mathrm{C}$ para $32^{\circ} \mathrm{C}$ ) na temperatura média máxima resultou em aumento da prevalência do BTV de $7 \%$ para $45 \%$. Assim, é possível supor que a prevalência para o BTV encontrada neste estudo seria maior se as amostras de soro tivessem sido coletadas na época das chuvas.

A fauna de Culicoides no Brasil ainda é pouco estudada e, até hoje, nenhum trabalho sobre o assunto foi encontrado, na literatura consultada, para o Estado do Mato Grosso do Sul. Contudo, em vista de a característica da manutenção da infecção do BTV ser possível apenas em regiões onde estão presentes vetores competentes, bem como em virtude de as condições climáticas serem favoráveis ao desenvolvimento de Culicoides, é possível supor que esses vetores ocorrem na região do presente estudo.

Para Leptospira, a frequência de 38,9\% de animais positivos descrita por Pellegrin et al. (1999) para bovinos criados no Pantanal Sul Mato-grossense, aproxima-se da encontrada nos rebanhos pesquisados. Outros autores relataram maiores prevalências para este Estado, como $62,3 \%$ (Favero et al., 2001) e 50,7\% (Tomich et al., 2007). Mesmo na região do estudo, a soroprevalência diferiu com o assentamento rural $(\mathrm{P}<0,01) \quad$ (Tab. 2), indicando influência de fatores ambientais na infecção do animal.

A Leptospira é sensível, e a presença de água de superfície, solos neutros a ligeiramente alcalinos, temperaturas elevadas, a existência de animais silvestres, bem como a presença de animais portadores da bactéria no rebanho, são características importantes para sua sobrevivência no ambiente e manutenção da infecção dos animais (Alonso-Andicoberry et al., 2001). Todas essas características estão presentes na região estudada, determinando condições favoráveis à disseminação e à manutenção da Leptospira endêmica.

A grande percentagem (48,3\%) de amostras soropositivas para pelo menos duas das doenças da reprodução, encontrada no presente estudo, pode representar maiores prejuízos à bovinocultura local. Correlação positiva entre ocorrência de aborto e diferentes associações de soropositividade para BoHV-1, BTV, Leptospira e diarreia bovina a vírus foi encontrada por Konrad (2003), com maior percentual de aborto observado em animais soropositivos justamente para os três agentes estudados no presente trabalho. Esse autor comenta que, devido à dificuldade do estabelecimento de um diagnóstico definitivo para o aborto, a implicação das doenças associadas à ocorrência desse sintoma é apenas um indício. A ocorrência de aborto, bem como de retenção de placenta, nos rebanhos bovinos dos assentamentos rurais pesquisados foi relatada pelas famílias assentadas e pode representar importante causa de perdas econômicas para esses rebanhos. BoHV-1, BTV e Leptospira devem ser considerados como possíveis causas da ocorrência desses abortos. Além do aborto, a mortalidade de animais, a perda de peso, a diminuição no índice de fertilidade e a queda na produtividade de leite devem ser consideradas como causas de perdas econômicas determinadas por esses microrganismos.

A idade do animal foi um fator de risco para a infecção por BoHV-1 $(\mathrm{P}<0,001)$, BTV $(\mathrm{P}<0,001)$ e Leptospira $(\mathrm{P}<0,01)$, determinando aumento da soropositividade com o aumento da idade. Nenhum bezerro foi positivo para BTV, apenas um foi positivo para Leptospira e dois foram positivos para BoHV-1 (Tab. 3). Vinte e quatro bezerros $(24 / 27,88,9 \%)$ e trinta e dois novilhos $(32 / 65,49,2 \%)$ foram negativos, ao mesmo tempo, para as três doenças pesquisadas. Vários autores relataram o aumento da idade do animal, geralmente superior a 24 meses, como fator determinante da maior soropositividade para BoHV-1 (Solis-Calderon et al., 2003), para BTV (Ward et al., 1994) e para Leptospira (AlonsoAndicoberry et al., 2001) e atribuíram este fato ao maior tempo de exposição do animal às condições que causam a infecção. Assim, a variável idade é importante na identificação de grupos de bovinos em risco para infecção por 
essas doenças no campo. Adicionalmente, para Leptospira, a infecção de animais jovens pode representar maior risco de dispersão da infecção no rebanho, uma vez que tem sido sugerido que a leptospirúria está relacionada à idade do animal com maior incidência em bezerros. Vacas maiores de três anos normalmente não são leptospirúricas (Alonso-Andicoberry et al., 2001).
A presença de animais soropositivos nos rebanhos pesquisados indica que as infecções por BoHV-1, BTV e Leptospira ocorrem nos assentamentos rurais de Corumbá, MS, uma vez que a vacinação para estes agentes não é praticada, sendo as prevalências encontradas compatíveis com rebanhos endêmicos.

Tabela 3. Soroprevalência de Herpesvírus bovino 1 (BoHV-1), vírus da língua azul (BTV) e Leptospira por categoria do animal, em criações de bovinos leiteiros de quatro assentamentos rurais de Corumbá, MS, 2003

\begin{tabular}{|c|c|c|c|c|c|c|}
\hline \multirow[b]{3}{*}{$\begin{array}{l}\text { Categoria do } \\
\text { animal }\end{array}$} & \multicolumn{6}{|c|}{ Amostra positiva (soro) } \\
\hline & \multicolumn{2}{|c|}{ BoHV-1* } & \multicolumn{2}{|c|}{ BTV* } & \multicolumn{2}{|c|}{ Leptospira** } \\
\hline & $\mathrm{n} / \mathrm{N}$ & $\begin{array}{c}\% \\
\text { (IC 95\%) }\end{array}$ & $\mathrm{n} / \mathrm{N}$ & $\begin{array}{c}\% \\
\text { (IC 95\%) }\end{array}$ & $\mathrm{n} / \mathrm{N}$ & $\begin{array}{c}\% \\
\text { (IC 95\%) }\end{array}$ \\
\hline Desconhecido & $33 / 63$ & $\begin{array}{c}52,4 \\
(39,4-65,1)\end{array}$ & $31 / 64$ & $\begin{array}{c}48,4 \\
(35,8-61,3)\end{array}$ & $35 / 64$ & $\begin{array}{c}54,7 \\
(41,7-67,2)\end{array}$ \\
\hline Vaca & $118 / 183$ & $\begin{array}{c}64,5 \\
(57,1-71,4)\end{array}$ & $130 / 183$ & $\begin{array}{c}71,0 \\
(63,9-77,5)\end{array}$ & $65 / 180$ & $\begin{array}{c}36,1 \\
(29,1-43,6)\end{array}$ \\
\hline Touro & $10 / 13$ & $\begin{array}{c}76,9 \\
(46,2-95,0)\end{array}$ & $9 / 13$ & $\begin{array}{c}69,2 \\
(38,6-90,9)\end{array}$ & $5 / 13$ & $\begin{array}{c}38,5 \\
(13,9-68,4)\end{array}$ \\
\hline Bezerro & $02 / 27$ & $\begin{array}{c}07,4 \\
(00,9-24,3)\end{array}$ & $00 / 27$ & $\begin{array}{c}00,0 \\
(00,0-12,8)\end{array}$ & $1 / 27$ & $\begin{array}{c}03,7 \\
(0,1-19,0)\end{array}$ \\
\hline Novilho & $16 / 66$ & $\begin{array}{c}24,2 \\
(14,5-36,4)\end{array}$ & $11 / 66$ & $\begin{array}{c}16,7 \\
(08,6-27,9)\end{array}$ & $19 / 65$ & $\begin{array}{c}29,2 \\
(18,6-41,8)\end{array}$ \\
\hline Total & $179 / 352 a$ & $\begin{array}{c}50,9 \\
(45,5-56,2)\end{array}$ & $181 / 353$ & $\begin{array}{c}51,3 \\
(45,9-56,6)\end{array}$ & $125 / 349 b$ & $\begin{array}{c}35,8 \\
(30,8-41,1)\end{array}$ \\
\hline
\end{tabular}

*Houve associação entre a frequência de animais positivos para o agente e a categoria do animal $(\mathrm{P}<0,001)$ pelo teste $\chi 2$. **Houve associação entre a frequência de animais positivos para o agente e a categoria do animal $(\mathrm{P}<0,01)$ pelo teste $\chi 2$. $\mathrm{n} / \mathrm{N}=$ Número de amostras positivas/Número total de amostras analisadas; IC $95 \%=$ Intervalo de confiança a $95 \%$ de probabilidade.

Desconhecido $=$ amostras de soro sem identificação da idade do animal; vaca $=$ animal com idade variando de 27 a 180 meses (média de 49,1 meses; $\mathrm{s}=19,2$ ); touro = animal com idade variando de 30 a 84 meses (média de 45,0 meses; $\mathrm{s}=$ $16,1)$; bezerro = animal com idade variando de nove a 12 meses (média de 11,0 meses; $\mathrm{s}=1,2$ ); novilho = animal com idade variando de 14 a 24 meses (média de 19,6 meses; $\mathrm{s}=3,7$ )

${ }^{\mathrm{a}}$ Para BoHV-1, uma amostra não foi analisada (total de amostras $=352$ ); ${ }^{\mathrm{b}}$ Para Leptospira quatro amostras não foram analisadas (total de amostras $=349$ ).

Palavras-chave: Herpesvírus bovino 1, vírus de língua azul, Leptospira, soroprevalência

\section{ABSTRACT}

This investigation was carried out in dairy cattle from four rural settlements of Corumbá, MS, Brazil, in order to assess the seroprevalence of bovine herpesvirus 1 (BoHV-1), bluetongue virus (BTV), and Leptospira; and the prevalence was 50.9\% (179/352), 51.3\% (181/353), and 35.8\% (125/349), respectively. Association between frequency of seropositive animals and evaluated rural settlements $(P<0.01)$ was found for Leptospira, and indicated the influence of environmental factors in bovine infection. Age was significantly related to BoHV-1 $(P<0.001)$, BTV $(P<0.001)$, and Leptospira infection $(P<0.01)$, showing higher number of infection among older animals. Once the bovine herds were not vaccinated, the presence of seropositive animals indicated that these infections occurred in rural settlements herds of Corumbá assayed, and certainly induced economical loss.

Keywords: BoHV-1, bluetongue virus, Leptospira, seroprevalence 


\section{AGRADECIMENTOS}

À Agência Estadual de Defesa Sanitária Animal e Vegetal do Mato Grosso do Sul - IAGRO, pela colaboração na coleta das amostras de soro bovino. À Fundação de Apoio ao Desenvolvimento do Ensino, Ciência e Tecnologia do Estado do Mato Grosso do Sul FUNDECT e à Empresa Brasileira de Pesquisa Agropecuária - Embrapa , pelo apoio financeiro. Ao Conselho Nacional de Desenvolvimento Científico e Tecnológico - $\mathrm{CNPq}$, pela concessão de bolsas as pesquisadoras Cláudia V. Serra, Edel F. Barbosa-Stancioli, Maria Rosa Q. Bomfim, Renata G.P. Tomich e Zélia I. P. Lobato.

\section{REFERÊNCIAS BIBLIOGRÁFICAS}

ALONSO-ANDICOBERRY， C.; GARCÍA-PEÑA, F.J.; ORTEGA-MORA, L.M. Epidemiología, diagnóstico y control de la leptospirosis bovina (Revisión). Invest. Agric. Prod. Sanid. Anim., v.16, p.205-225, 2001

ARAÚJO, V.E.M.; MOREIRA, E.C.; NAVEDA, L.A.B. et al. Frequência de aglutininas anti-Leptospira interrogans em soros sanguíneos de bovinos, em Minas Gerais, de 1980 a 2002. Arq. Bras. Med. Vet. Zootec., v.57, p.430-435, 2005.

COSTA, J.R.R.; LOBATO, Z.I.P.; HERRMANN, G.P. et al. Prevalência de anticorpos contra o vírus da língua azul em bovinos e ovinos do Sudoeste e Sudeste do Rio Grande do Sul. Arq. Bras. Med. Vet. Zootec., v.58, p.273-275, 2006.

FAINE, S. Guidelines for the control of leptospirosis. Geneva: WHO, 1982. 172p. (Offset Publication, 67).

FAVERO, A.C.M.; PINHEIRO, S.R.; VASCONCELLOS, S.A. et al. Leptospirose bovina: variantes sorológicas predominantes em colheitas efetuadas no período de 1984 a 1997 em rebanhos de 21 estados do Brasil. Arq. Inst. Biol., v.68, p.29-35, 2001.

KONRAD, P.A. Inquérito sorológico de agentes infecciosos que afetam a reprodução de bovinos leiteiros em Minas Gerais, 2001-2002. 2003. 40f. Dissertação (Mestrado) - Escola de Veterinária, Universidade Federal de Minas Gerais, Belo Horizonte.
LAGE, A.P.; CASTRO, R.S.; MELO, M.I. et al. Prevalence of antibodies to bluetongue, bovine herpesvirus 1 and bovine viral diarrheamucosal disease viruses in water buffaloes in Minas Gerais state, Brazil. Rev. Elev. Med. Vet. Pays Trop., v.49, p.195-197, 1996.

MANUAL of diagnostic tests and vaccines for terrestrial animals. Paris: OIE, 2004. Disponível em: $<$ http://www.oie.int/eng/normes/mmanual/A_summry.htm>. Acessado em: 20 set. 2007.

PEARSON, J.; JOCHIM, M. Protocol for the immunodiffusion test for blue-tongue. Proc. Am. Assoc. Vet. Lab. Diagn., v.22, p.463-471, 1979.

PELLEGRIN, A.O.; GUIMARÃES, P.H.S.; SERENO, J.R.B. et al. Prevalência da leptospirose em bovinos do pantanal mato-grossense. Corumbá: Embrapa Pantanal, 1999. 9p. (Comunicado Técnico, 22).

PELLEGRIN, A.O.; SERENO, J.R.B.; LEITE, R.C. et al. Doenças da reprodução em bovinos no Pantanal: ocorrência de animais soropositivos para os vírus da rinotraqueite infecciosa bovina, diarreia bovina a vírus e língua azul. Corumbá: Embrapa Pantanal, 1997. 7p. (Comunicado Técnico, 20).

SOARES, L.A.; PEREIRA, D.A.C. Neutralizing antibodies against bovine viral diarrhea-mucosal disease (BVD) in cattle sera from São Paulo state, Brazil. Rev. Microbiol., p.88-593, 1980.

SOLIS-CALDERON, J.J.; SEGURA-CORREA, V.M.; SEGURA-CORREA, J.C. et al. Seroprevalence of and risk factors for infectious bovine rhinotracheitis in beef cattle herds of Yucatan, México. Prev. Vet. Med., v.57, p.199-208, 2003.

SORIANO, B.M.A. Caracterização climática de Corumbá-MS. Corumbá: Embrapa CPAP, 1997. 25p. (Boletim de Pesquisa, 11).

TOMICH, R.G.P.; BOMFIM, M.R.Q.; KOURY, M.C. et al. Leptospirosis serosurvey in bovines from Brazilian Pantanal using IgG ELISA with recombinant protein LipL32 and microscopic agglutination test. Braz. J. Microbiol., v.38, p.674-680, 2007.

WARD, M.P. Climatic factors associated with the prevalence of bluetongue virus infection of cattle herds in Queensland, Australia. Vet. Rec., v.134, p.407-410, 1994.

WARD, M.P.; CARPENTER, T.E.; OSBURN, B.I. Host factors affecting seroprevalence of bluetongue virus infections of cattle. Am. J. Vet. Res., v.55, p.916920, 1994. 